\title{
Recipients' Perceptions Regarding Transplantation of Surgically Restored Cancerous Kidneys in Japan
}

\author{
Miyako Takagi
}

\begin{abstract}
Patients with renal failure wait an average of 14 years to receive a transplant after registration on the waiting list in Japan. Many patients must therefore depend on a living donor. Between January 2012 and March 2013, a questionnaire was sent to three hospitals where transplants had been performed. We obtained responses from 152 recipients receiving kidneys from their spouses concerning their physical and psychological condition after transplantation and their perceptions of living donor kidney transplantation. Afterwards, we asked recipients' opinions about transplantation of surgically restored cancerous kidneys as a new source for donor In response to questions regarding the physical condition of the recipient after kidney transplantation, $\mathbf{7 8 . 3 \%}$ respondents reported that recipients felt good or very good, whereas $4.6 \%$ recipients felt less than normal or bad. In response to the questions regarding the psychological condition of the recipient after kidney transplantation, $69.1 \%$ recipients reported feeling good or very good, and $3.9 \%$ recipients felt less than normal or bad. One hundred thirty-one recipients $(86.2 \%)$ recognized living donor transplantation as ongoing medical care, and 11 recipients $\mathbf{( 7 . 2 \% )}$ ) perceived it only as temporary medical care. No recipient thought the medical care which they received to be a problem. In response to questions regarding restored kidney transplantation, 124 recipients $(\mathbf{8 1 . 6 \%})$ recognized it as medical care and 15 recipients $(9.9 \%)$ perceived it as only temporary medical care. Five recipients $(3.3 \%)$ thought it had a problem as medical care because of the risk in cancer recurrence. The fact that more than $80 \%$ recipients accepted restored kidney transplantation as medical care compares favorably with the results of the survey regarding living donor transplantation $(86.2 \%)$. Nevertheless, this practice is currently not allowed in Japan. In response to the question, "If restored kidney transplantation had been possible when you underwent the procedure, what would you have chosen, either living donor transplantation or restored kidney transplantation?" a total of 51 recipients $(33.6 \%)$ wanted to choose restored kidney transplantation, despite the possible 5-year recurrence rate of cancer of $6 \%$.
\end{abstract}

Index Terms-Living donor transplantation, recipients' perceptions, restored kidney transplantation, shortage of organs.

\section{INTRODUCTION}

Thousands of patients in Japan await transplantation from brain-dead or clinically dead donors, but only 110 such surgeries were performed in Japan in 2012 [1]. Patients wait an average of 14 years to receive a transplant after

Manuscript received August 9, 2013; revised October 15, 2013. This work was supported by a grant from Grants-in-Aid for Scientific Research (C) 23613009 of the Japanese Society for the Promotion of Science.

Miyako Takagi is with the University Research Center, Nihon University, 4-8-24, Kudan-minami, Chiyoda-ku, Tokyo, 102-8275, Japan (e-mail: takagi.miyako@ nihon-u.ac.jp). registration on the waiting list, and approximately 300,000 people across Japan must receive dialysis or depend on a living donor for survival. In order to increase the number of donors, Japanese government urges citizens to declare their intentions regarding organ donation on their driver's licenses, and revised the Organ Transplant Law in 2010. However, these policies have not worked well.

The ratio of living donor renal transplantations to whole transplants is approximately $90 \%$ in Japan, but it is less than $50 \%$ in the United States [2]. Spouses are an important source of living donor kidney grafts because, despite poor human leukocyte antigen (HLA) matching, the graft survival rate is similar to that of parental donor kidneys [3]. The ethics of living donor transplantation have been frequently discussed, and live donor nephrectomy for renal transplantation has become widespread. Because surgical techniques and outcomes have improved, this practice has expanded. However, living organ donation presents an ethical dilemma, in which physicians must risk the life of a healthy person to save or improve the life of a patient. The first tenet of the Hippocratic Oath of professional medical ethics is nonmaleficence [4]. In light of this tenet, living organ donation seems morally contestable. However, because this procedure is performed at the donor's request and for the physical benefit of the recipient, the principles of respect for the donor's autonomy and beneficence of the recipient generally outweigh the infringement of the principle of nonmaleficence.

On the other hand, the cost of dialysis averages 5-6 million yen $(\$ 50,000-60,000)$ per patient per year [5], and almost all treatment expenses for dialysis are paid by the Japanese National Health Insurance system. The ratio of total dialysis expense to national medical expenditure is roughly $5 \%$. Since the national medical expenditure in 2012 was 38.4 trillion yen ( $\$ 384$ billion) [6], the total dialysis expense would be calculated with 1.9 trillion yen ( $\$ 19$ billion). The cost of the transplant is much lower than that of dialysis. The average cost for transplantation, including the transplant surgery and medical care for the first postoperative year, averages 4 million yen $(\$ 40,000)$. After the first year, costs for transplantation average 1.5 million yen $(\$ 15,000)$ mostly for medications to prevent rejection [7]. From an aspect of the medical expenses reduction, shifts from dialysis to transplant may be necessary.

Total nephrectomy is often performed as a treatment for small renal tumors $(\leq 4 \mathrm{~cm})$. Many of these nephrectomized kidneys could be successfully transplanted after surgical restoration with satisfactory results [8].

Because of the lack of necessary evidence for the potential success of restored kidney transplantation, this is currently 
not allowed in Japan. The issue of cancer recurrence is a concern in restored kidney transplantation. The 5-year recurrence rate of cancer after restored kidney transplantation remains undetermined and Nicol et al supposed it is less than 1 out of 50 cases $(0.5 \%)$ [9], however, that after radical nephrectomy or partial nephrectomy is reported to be less than $6 \%[10]$.

In this study, a questionnaire survey was conducted in transplantation recipients with their experience of receiving a kidney from their spouses to determine their physical and psychological condition after transplantation and their perceptions of living donor kidney transplantation. Afterwards, recipients' opinions regarding transplantation of surgically restored cancerous kidneys as a new source for donor were investigated.

\section{METHODS}

\section{A. Sample Size and Sampling Method}

In this study, recipients who had undergone spousal renal donor transplantation were selected. Between January 2012 and March 2013, a questionnaire was sent to three hospitals where transplants had been performed. At two of the hospitals, a hospital worker sent a questionnaire to recipients, and respondents sent it back to the hospital. In another hospital, a hospital worker distributed the questionnaire to patients at a follow-up examination after transplantation, and respondents sent it back to our research center directly. In total, responses were obtained from 152 recipients. The questionnaire is provided in the Appendix.

\section{B. Statistical Analysis}

This analysis was used descriptive statistics.

\section{Ethical Considerations}

This study was approved by the ethical review committee in the Medical Department, Nihon University.

\section{RESULTS AND DisCUSSION}

\section{A. Gender Balance}

In total, 43 husbands (28.3\%) and 108 wives (71.1\%) were donors in this survey (Table I). Thus, a gender bias may have been present with regard to the number of donations from female living donors. Two of 3 kidneys were donated by wives in this study. In Switzerland, most living organ recipients are male [11]. In general, men are breadwinners in the family. Women are more often expected to act as donors, although no clear explanation exists for this imbalance. Donors may want recipients to live for their own sake, for that of the family, or for economic reasons. Thus, the decision to donate may have been partly related to the donors' requirements [12]. In addition, women may have felt more pressure from family and friends to donate than men.

\section{B. Physical and Psychological Condition of Recipients after Kidney Transplantation}

In response to questions regarding the physical condition of the recipient after kidney transplantation, $78.3 \%$ respondents reported that recipients felt good or very good, whereas $4.6 \%$ recipients felt less than normal or bad (Table II). When donors considered the physical condition of recipients, $66.2 \%$ reported that the recipients looked good or very good, whereas $6.3 \%$ stated that recipients looked less than normal or bad (unpublished data).

TABLE I: WHO WAS THE KIDNEY DONOR?

\begin{tabular}{lrc}
\hline \multicolumn{3}{c}{ TABLE I: WHO WAS THE KIDNEY DONOR? } \\
\hline no answer & $n$ & $\%$ \\
husband & 1 & 0.7 \\
wife & 43 & 28.3 \\
\hline \hline
\end{tabular}

TABLE II: PHYSICAL CONDITION OF THE RECIPIENT AFTER KIDNEY TRANSPLANTATION

\begin{tabular}{lrr}
\hline \multicolumn{3}{c}{ TRANSPLANTATION } \\
\hline no answer & $n$ & $\%$ \\
very good & 3 & 2.0 \\
good & 65 & 42.8 \\
normal & 54 & 35.5 \\
Less than normal & 23 & 15.1 \\
bad & 5 & 3.3 \\
\hline \hline
\end{tabular}

In response to the questions regarding the psychological condition of the recipient after kidney transplantation, $69.1 \%$ recipients reported feeling good or very good, and $3.9 \%$ recipients felt less than normal or bad (Table III). When donors considered the psychological condition of recipients, they reported that $57.1 \%$ recipients looked good or very good and $5.6 \%$ recipients looked less than normal or bad (unpublished data).

TABLE III: PSYCHOLOGICAL CONDITION OF THE RECIPIENT AFTER KIDNEY TRANSPLANTATION

\begin{tabular}{lrr}
\hline \hline & $n$ & $\%$ \\
\hline no answer & 3 & 2.0 \\
very good & 51 & 33.6 \\
good & 54 & 35.5 \\
normal & 38 & 25.0 \\
Less than normal & 4 & 2.6 \\
bad & 2 & 1.3 \\
\hline \hline
\end{tabular}

Because donors had observed the recipients suffering for a long time with kidney disease and dialysis, donors may have had low expectations of the physical or psychological condition of the recipients.

\section{Experience with Living Donor Transplantation}

One hundred thirty-one recipients $(86.2 \%)$ recognized living donor transplantation as ongoing medical care, and 11 recipients $(7.2 \%)$ perceived it only as temporary medical care. No recipient thought the medical care which they received to be a problem (Table IV).

Respondents were also provided with space to write a free answer. Some expressed a sense of guilt because the transplantation had been unsuccessful and described changes in attitude on part of the relatives.

As a definition of words, 'medical care' is regular medical care used for a long term, and 'temporary medical care' means more likely to be changed to the different medical care 
in the near future.

TABLE IV: WHAT Do YOU THINK ABOUT LIVING DONOR TRANSPLANTATION FROM YOUR EXPERIENCE?

\begin{tabular}{lrc}
\multicolumn{3}{c}{ TRANSPLANTATION FROM YOUR EXPERIENCE? } \\
\hline \hline no answer & $n$ & $\%$ \\
recognized as medical care & 5 & 3.3 \\
recognized as temporary medical care & 131 & 86.2 \\
had a problem as medical care & 0 & 7.2 \\
others & 5 & 0 \\
\hline \hline
\end{tabular}

In a sub-analysis, we classified and compared the responses of respondents into those by respondents who were $<60$ years of age and those who were $\geqslant 60$ years of age, respectively (Table V). For questions regarding medical care, $13.0 \%$ and $6.2 \%$ respondents aged $<60$ years and $\geqslant 60$ years, respectively, perceived living donor transplantation as temporary medical care. Therefore, more number of younger recipients tended to regard living donor renal transplantation as temporary medical care. They may think that regenerative medicine from ES cells or iPS cells is replaced for a living donor.

TABLE V: WHAT DO YOU THINK ABOUT LIVING DONOR TRANSPLANTATION FROM YOUR EXPERIENCE? (SUB-ANALYSIS IN $<60$ Y OR $\geqq 60 \mathrm{Y}$ )

\begin{tabular}{lcccc}
\hline \hline \multicolumn{1}{c}{ Age of the recipient } & $<60 \mathrm{y}$ & \multicolumn{3}{c}{$\geqq 60 \mathrm{y}$} \\
\hline \hline & $n$ & $\%$ & $n$ & $\%$ \\
\hline no answer & 2 & 8.7 & 3 & 2.3 \\
$\begin{array}{l}\text { recognized as medical care } \\
\text { recognized as temporary } \\
\quad 17\end{array}$ & 3 & 13.0 & 8 & 6.2 \\
$\begin{array}{l}\text { medical care } \\
\text { had a problem as medical care }\end{array}$ & 0 & 0 & 0 & 0 \\
others & 1 & 4.4 & 4 & 3.1 \\
\hline \hline
\end{tabular}

\section{Innovative Practice in Japan (Restored Kidney} Transplantation)

In the United States, approximately 17,000 renal transplantations are performed yearly, primarily from brain-dead donors. However, the number of donors is insufficient to meet the need because nearly 100,000 patients are on the waiting list for renal transplantation [13]. Therefore, organs that were not previously used for transplantation are now being used. The criteria for organ donation have been extended to include organs from elderly donors (double kidneys to a single recipient) and infectious organs (infected donor to infected recipient, e.g. with hepatitis) [2].

In Japan, different measures have been taken to increase the number of donors. The government urges citizens to declare their intentions regarding organ donation on their driver's licenses. In addition, the Organ Transplant Law was revised in 2010. Under the reformed law, organ donation is possible with the agreement of the family, even if the intention of the donor cannot be confirmed. Although these policies have been established, considerable changes in organ donation trends have not yet been observed in Japan.

Under these circumstances, one doctor (Dr. M) decided to use other kinds of kidneys. Between 1991 and 2006, he performed 42 restored kidney transplantations. Restored kidneys include cancerous kidneys (tumors must be $\leq 4 \mathrm{~cm}$ in diameter), which were removed from patients. The tumors are then carefully excised, and the kidneys surgically restored. Further, they are transplanted into individuals on the waiting list.

Many small renal tumors are nephrectomized in Japan, resulting in the disposal of an excessive number of discarded kidneys every year. It is believed that using discarded cancerous kidneys for transplantation may help to compensate for donor shortage. However, this practice is currently disallowed in Japan because of the lack of necessary evidence. The issue of cancer recurrence is a concern in restored kidney transplantation. The 5-year recurrence rate of cancer after restored kidney transplantation remains undetermined. Nicol et al. supposed that it may be observed in less than one of 50 cases $(0.5 \%)$ [9]. However, the recurrence rate after radical or partial nephrectomy is reported to be $<6 \%$ [10]. In our survey, we asked recipients a question on the assumption of a 5-year recurrence rate after restored kidney transplantation of $6 \%$. This rate seems very high compared with the reality.

\section{E. Opinion of Recipients Regarding Restored Kidney Transplantation}

In response to the question, "What do you think about restored kidney transplantation?" 124 recipients $(81.6 \%)$ recognized restored kidney transplantation as medical care, and 15 recipients $(9.9 \%)$ perceived it as only temporary medical care. Five recipients $(3.3 \%)$ thought it had a problem as medical care because of the risk in cancer recurrence (Table VI). The fact that more than $80 \%$ recipients accepted restored kidney transplantation as medical care compares favorably with the results of the survey regarding living donor transplantation $(86.2 \%)$. Nevertheless, this practice is currently not allowed in Japan.

TABLE VI: WHAT DO YOU THINK ABOUT RESTORED KIDNEY TRANSPLANTATION FROM YOUR EXPERIENCE?

\begin{tabular}{lrr}
\hline \hline & $n$ & $\%$ \\
\hline no answer & 6 & 3.9 \\
recognized as medical care & 124 & 81.6 \\
recognized as temporary medical care & 15 & 9.9 \\
had a problem as medical care & 5 & 3.3 \\
others & 2 & 13 \\
\hline \hline
\end{tabular}

TABLE VII: IF RESTORED KIDNEY TRANSPLANTATION HAD BEEN POSSIBLE, WOULD YOU HAVE CHOSEN EITHER LIVING DONOR TRANSPLANTATION OR RESTORED KIDNEY TRANSPLANTATION?

\begin{tabular}{llr}
\hline \hline & $n$ & $\%$ \\
\hline no answer & 12 & 7.9 \\
I choose living donor transplantation & 65 & 42.8 \\
I choose restored kidney transplantation & 51 & 33.6 \\
I cannot decide which one to choose & 24 & 15.8 \\
\hline \hline
\end{tabular}

In response to the next question, "If restored kidney transplantation had been possible when you underwent the procedure, what would you have chosen, either living donor transplantation or restored kidney transplantation?" a total of 51 recipients $(33.6 \%)$ wanted to choose restored kidney transplantation (Table VII), despite the possible 5-year 
recurrence rate of cancer of $6 \%$.

The recipients who responded to the survey may have had mixed emotions. They were very glad to become healthy after transplantation; however, they expressed a sense of guilt or uneasiness regarding the status of donors having only a single kidney, and they were worried about the donors' health.

In Table VIII, recipients' answers from Table VII are classified into two categories according to their physical condition after kidney transplantation. In the category of recipients who felt better after transplantation, 30 recipients (46.2\%) wanted to choose restored kidney transplantation compared with those who wanted to choose living donor transplantation (33.8\%). Recipients who reported good health after transplantation may have been more concerned regarding donors' health.

TABLE VIII: RESPONSES CLASSIFIED BY PHYSICAL CONDITION AFTER KIDNEY TRANSPLANTATION (SUB-ANALYSIS IN $\geqq$ GOOD OR $\leqq$ USUAL)

\begin{tabular}{|c|c|c|c|c|}
\hline \multirow{2}{*}{$\begin{array}{l}\text { Physical condition after } \\
\text { transplantation }\end{array}$} & \multicolumn{3}{|c|}{$\geqq \operatorname{good}$} & \multirow{2}{*}{$\begin{array}{c}\leqq \text { usual } \\
\%\end{array}$} \\
\hline & $n$ & $\%$ & $\mathrm{n}$ & \\
\hline no answer & 5 & 7.7 & 4 & 7.4 \\
\hline $\begin{array}{l}\text { I choose living donor } \\
\text { transplantation }\end{array}$ & 22 & 33.8 & 28 & 51.9 \\
\hline $\begin{array}{l}\text { I choose restored kidney } \\
\text { transplantation }\end{array}$ & 30 & 46.2 & 12 & 22.2 \\
\hline $\begin{array}{l}\text { I cannot decide which one } \\
\text { to choose }\end{array}$ & 8 & 12.3 & 10 & 18.5 \\
\hline
\end{tabular}

Guidelines on Renal Transplantation (2009) published by the European Association of Urology [14] state the following: "Due to a low risk of recurrence, kidneys with small renal cell carcinoma (RCC) can be considered for local excision and transplantion after the recipient has given informed consent. The risk of RCC transmission to the contralateral kidney and/or to other organs is even lower." In contrast, the Guidelines for Living Donor Kidney Transplantation (2011) in the United Kingdom [15] state the following: "If the tumor is $4 \mathrm{~cm}$ or larger, donation should only be contemplated if excision of the tumor is possible because of the risk of subsequent symptoms. If the tumor is small, for example, $\leqq 1$ $\mathrm{cm}$ and its position makes removal particularly difficult, then donation followed by bi-annual ultrasound surveillance is reasonable and has also been published as a case report. For tumors ranging from $1 \mathrm{~cm}$ to $<4 \mathrm{~cm}$ in diameter, there is little evidence available and management will depend, in a large part, on the position of the tumor."

In this survey, more than $30 \%$ transplant recipients preferred restored kidney transplantation to living donor transplantation. Some recipients may have preferred to avoid invasive surgery for another person. For such people option called the restored kidney transplantation should be provided. In regarding to this option, recipients must understand the risks and benefits of the procedure, and during counseling, data must be provided to demonstrate the statistical possibilities of cancer recurrence in restored kidneys.

With reference to the overseas guidelines, the Japanese government should consider the introduction and approval of restored kidney transplantation.

\section{CONCLUSIONS}

Partial resection in renal tumor has not always been performed because total nephrectomy causes minimal damage and is technically easier than partial resection. Therefore, total nephrectomy is often performed as treatment for small renal tumors, leaving a considerable number of potentially transplantable kidneys to be discarded every year. Because cancerous kidneys are being discarded anyway, fewer ethical issues may be associated with restored kidney transplantation compared with living donor transplantation.

In this survey it was shown that the recipients in living donor transplantation expressed a sense of guilt or uneasiness regarding the status of donors having only a single kidney, and they were worried about the donors' health.

Clinical research is currently underway to determine the feasibility of restored kidney transplantation as a method of alleviating the long waiting time and easing the suffering of patients who require transplantation. Some concern has been expressed regarding the possibility of transmitting disease after restored kidney transplantation. For this issue, no recurrence was seen even after 42 months in subsequent observation on 10 kidney transplantations after surgical restoration [unpublished data].

Patients have been known to resist the idea of receiving a previously cancerous kidney. However medical transplantation originally started and has been developed based on the assumption that human bodies are medical resources. Utilizing kidneys discarded due to cancer and other diseases is consistent with this outlook and could be viewed as a way of recycling unwanted resources [16]. Previously cancerous donor kidneys that have been restored after nephrectomy may be added to the donor pool to relieve the pressure on families and recipients.

\section{APPENDIX}

Questionnaire:

1) The day when questionnaire was filled out.

2) Are you the wife or husband of the kidney donor?

3) How old was the donor at the time of renal transplantation? (20-29, 30-39, 40-49, 50-59, 60-69, \70 years)

4) How old were you at the time of renal transplantation? (20-29, 30-39, 40-49, 50-59, 60-69, \70 years)

5) When was the transplant surgery performed?

6) How many years had you been married when the surgery was performed?

7) How long were you on dialysis?

8) What is your religion?

9) After kidney transplantation, what was your physical condition?

10) After kidney transplantation, what was your psychological condition?

11) After kidney transplantation, did conjugal relations between you change?

12) What do you think about living donor transplantation from your experience?

13) Total nephrectomy is often performed as a treatment for small renal tumors $(\leqq 4 \mathrm{~cm})$. Many of these nephrectomized kidneys could be successfully transplanted after surgical restoration with satisfactory 
results. However this is currently not allowed in Japan because of the lack of necessary evidence. The issue of cancer recurrence is a concern in restored kidney transplantation. The 5-year recurrence rate of cancer after restored kidney transplantation remains undetermined and we estimated it to be $6 \%$. How do you think about restored kidney transplantations?

14) If those days when you underwent transplant, restored kidney transplantation was possible, what kind of choice did you do, living donor transplantation or restored kidney transplantation?

\section{ACKNOWLEDGMENT}

The author is deeply grateful to Dr. M. Mannami of the Department of Urology, Uwajima Tokushukai Hospital, Prof K. Tanabe of the Department of Urology, Tokyo Women's Medical University, and Dr. N. Mitsuhata of the Department of Urology, Kure Kyosai Hospital for permitting distribution of the questionnaire.

\section{REFERENCES}

[1] Japan Organ Transplant Network. [Online]. Available: http://www.jotnw.or.jp/.

[2] J .Sageshima. (February 2013). The United States which a living renal transplantation from an anonymous donor increases. Nikkei Medical KUROFU Net. [Online]. Available: http://backnumber.kurofunet.jp/article/65737316.html.

[3] B. V. Shah, P. Rajput, V. Waghmare, and A. Aiyangar, "Spousal kidney transplant," Journal of Nephrology and Renal Transplantation vol. 2, no. 1, pp. 16-22, 2009.

[4] J. F. Childress and T. L. Beauchamp, Principles of Biomedical Ethics, 6th ed., Oxford Univ. Press, U.K, 2009

[5] Dialysis Treatment Network. (2010). [Online]. Available: http://www.quoteplatform.com/touseki/kiso03.php.
[6] Ministry of Health. (2013). Labour and Welfare. [Online]. Avaiable: http://www.mhlw.go.jp/topics/medias/year/12/d1/iryouhi_data.pdf.

[7] Medical expenses of renal transplantation. (2011). [Online]. Available: http://www.novartis.co.jp/life/ishoku/toseki/006.html.

[8] M. Mannami, R. Mannami, N. Mitsuhata, M. Nishi, Y. Tsutsumi, K. Nanba, and S. Fujita, "Last resort for renal transplant recipients, 'restored kidneys' from living donors/patients," Am J Transplant, vol. 8, no. 4, pp. 811-818, 2008

[9] D. Nicol and S. Fujita, "Kidneys from patients with small renal tumours used for transplantation: Outcomes and results," Curr Opin Urol., vol. 21, no. 5, pp. 380-385, 2011.

[10] H. V. Poppel, "Efficacy and safety of nephron-sparing surgery," International Journal of Urology, vol. 17, pp. 314-326, 2011.

[11] G. T. Thiel, C. Nolte, and D. Tsinalis, "Gender Imbalance in living kidney donation in Switzerland," Transplantation Proceedings, vol. 37, no. 2, pp. 592-594, 2005.

[12] M. Takagi, "Feelings of living donors regarding spousal renal donor transplantation," in Proc. of $13^{\text {th }}$ Asian Bioethics Conf., 2012, pp. 181-191.

[13] Health Resources and Services Administration/Organ Procurement and Transplantation Network: Data. [Online]. Available: http://optn.transplant.hrsa.gov/data/.

[14] Guidelines on Renal Transplantation, European Association of Urology, 2009.

[15] United Kingdom Guidelines for Living Donor Kidney Transplantation the British Transplantation Society and the Renal Association, 2011

[16] T. Awaya, Human Body Parts Business, $1^{\text {st }}$ ed., Tokyo, Japan: Kodansha, 1999.

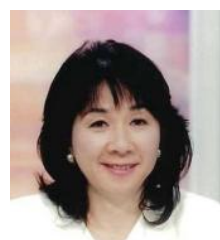

Miyako Takagi is a professor of University Research Center at Nihon University. Her research interests include ethical, legal and psychosocial aspect of organ transplantation, embryonic stem cell research and neuroethics. She is a member of Bioethics Committee in Japanese Cabinet Office, and also she is vice president in Asian Bioethics Association. She received her Docteur d'Université ès Sciences, Université PARIS VII. 